Article

\title{
Health Consciousness, Smog Consciousness and Chinese Elderly Migrant Workers' Preferred Retirement Place
}

\author{
Feng Wang ${ }^{1}$, Jin Fan ${ }^{2}{ }^{\mathbb{D}}$, Ann Reisner ${ }^{3}$ and Hong Mi ${ }^{2, *}$ \\ 1 School of Economics and Management, Northwest University, 229 North Tai Bai Avenue, \\ Xi'an 710069, China; wangf@nwu.edu.cn \\ 2 School of Public Affairs, Zhejiang University, 866 Yuhangtang Road, Hangzhou 310058, China; \\ fanjin92@163.com \\ 3 Department of Media and Cinema Studies, University of Illinois at Urbana-Champaign, 242 Gregory Hall, \\ 810 S. Wright Street, Urbana, IL 61801, USA; reisnera@illinois.edu \\ * Correspondence: spsswork@163.com; Tel.: +86-186-5712-6326
}

Received: 28 September 2017; Accepted: 30 October 2017; Published: 3 November 2017

\begin{abstract}
Although those who migrated fairly early in the Chinese diaspora are reaching retirement age, their choice of retirement location will be affected by significant rural-urban disparities in medical insurance and service, pension, environment management, and public education. The lifestyle and savings for migrant workers over 45 years old are unique; they have received the wages of urban workers but are still tied to agricultural residential identities. A field survey of 173 elderly migrant workers in $\mathrm{Xi}^{\prime}$ an examined the relationship between preferred place of retirement and health, smog, and health environmental consciousness. Among the sample, $70.5 \%$ preferred to return home for retirement; $16.8 \%$, to stay away from home; and $12.7 \%$ had not yet considered where they would live in retirement. Based on regression results, migrant workers who were more concerned about their personal health, less concerned about the effects of city smog, who had property in rural areas and who were less educated were significantly more likely to say that they would return to rural areas for retirement. It is suggested that the narrowing the gap in retirement service and medical service between rural and urban areas could be an effective way for the government to deal with future retirement issues and provide equalized retirement services for elderly migrant workers.
\end{abstract}

Keywords: elderly migrant workers; retirement place; personal health consciousness; smog consciousness

\section{Introduction}

While the Chinese government has developed policies to promote urban-rural integration since the 1980s [1], the disparity between urban and rural remains relatively vast, including a number of factors that could affect retirement choices. These include disparities in medical insurance and services, pension, and environmental management. For most of the population, the differences between urban and rural support systems will not directly affect their choice of retirement location, overwhelmingly urban residents will choose to remain urban and rural residents to remain rural. However, one significant population in China has strong ties to both agricultural and urban residences and could conceivably choose to live in either location-internal migrant workers with "agricultural Hukou". (Hukou is a record of household registration system in mainland China, owning two types as "agricultural Hukou" and "non-agricultural Hukou".)

China defines a "migrant worker" as a person who migrates without official approval, that is, a "temporary resident" in areas other than his or her official Hukou [2]. (As defined by Zhang [3], "migrant worker" includes both those who stay in rural areas and those who move to urban areas 
and engage in secondary or tertiary industries.) Migrant workers are now a significant segment of the active working population, more than $20 \%$ of the national workforce [4]. In 2015, local migrant workers comprised just under $40 \%$ of the migrant population (108.63 million), while 168.84 million migrant workers, fully $60 \%$ of the migrant population, migrated to urban areas [4]. These urban migrant workers are one of the cornerstones for promoting equitable economic and social development. That is, not only do migrant workers improve their personal living standards, they simultaneously reduce the gap between urban and rural areas.

While industrialization and urbanization tend to attract more rural laborers, especially young laborers, the intergenerational conversion of the population structure produced by the one-child policy in China has led to a situation in which older migrant workers (born between 1964 and 1972) are rapidly approaching the age to consider retirement while not enough young laborers have been born to fill the gaps in the labor force left by the baby boomers. As a population, then, migrant workers are aging. The average age of migrant workers in 2010 was 35.5; by 2014, the average age had climbed to 38.3. At the same time, the number and percentage of migrant workers over 50 years old increased [4]. (In China, the official retirement age for females is 50, for males 60.)

In China, pensions are differentiated by Hukou and the retiree's pre-retirement job. For urban employees' basic pension insurance, the average pension of enterprise retirees and separating employees is 2061 RMB (298 USD) per month, and the pension replacement rate of enterprise retirees is $67.5 \%$. In the new rural social pension insurance program, the basic average pension was $55 \mathrm{RMB}$ (8 USD) per month when the policy started in 2009 and increased to 70 (10 USD) RMB per month in 2014 [5]. Migrant workers staying in urban areas when they retire will receive pension insurance authorized under their agricultural Hukou. In addition, migrant workers' medical care is tied to joining the cooperative medical system, which is regulated by their agricultural Hukou.

Although retiring and near-retirement migrant workers have stepped into an urban milieu, they are still bureaucratically tied to rural support systems [6]. If migrant workers choose to return home, they are expected to place a large burden on the already underdeveloped medical social support systems just in terms of increased numbers. If they return home carrying illnesses developed in urban areas, they would further increase the demands of medical care in a rural medical system that is already stressed [7]. At the same time, migrant workers who choose to retire in urban areas face difficulties (discussed in more detail below) living outside of their Hukou. Given the strains that migrant retirement decisions could place on a number of support institutions, the factors that migrant workers are considering in retirement locations are of considerable interest to those agencies that will be required to service the pensioners.

This paper chooses migrant workers aged between 45 and 65 with "agricultural Hukou" and no less than six months' living experience in urban cities as interviewees. The study examines whether migrant workers have given any thought to retirement and what factors (e.g., smog consciousness, self-identified health status) have influenced their decision. The exploration of this relationship could provide an academic reference for public service and investment toward rural areas aiming to reduce the huge gap in medical, retirement, and education caused by a dual economy.

\section{Literary Review}

\subsection{Migrant Worker: Urban-Rural Selectivity}

In the mid-1980s, economic system reforms that privileged nonagricultural economic powerhouses created opportunities for migrant workers willing to relocate to urban areas. As a result, a great number of migrant workers voluntarily began transferring to secondary and tertiary industries in cities. However, the household registration system (Hukou) which tied government authorized benefits to registered housing created a disjunction for those workers whose actual location differed from their registered location. Since the household registration system which regulates identities in China does not allow workers to easily change their registration, a new class of worker developed 
that accepted a long-term division of registered and actual residence [8,9] even though migrant status inflicts severe disadvantages.

Migrant workers-also called Liang-Qi people—cannot fully integrate into the urban areas. For one, migrant workers generally are paid lower salaries than their local counterparts. In addition, depending on the specific province, migrant workers' children may not have the same access to the educational system or to college exams. And, to complicate matters, the bureaucratic services that are tied to their agricultural Hukou, including full use of the better medical resources in the urban areas, are difficult, awkward or impossible to obtain in their actual urban location.

Even with these disadvantages, migrant workers have a variety of reasons to stay as permanent or semi-permanent migrants. Chu et al. [10], for example, propose that migrants who develop their own business have the potential to improve their income distinctively not only for themselves but for their families. Temporary migration for migrant workers is, in fact, not merely a personal decision, but an economic decision of the family, a rational choice based on a combination of social and economic factors including family goals, pursuit of higher return on human capital and fundamental social support services such as the quality of primary education.

While the 13th Five-Year Plan specifically includes the objective of reducing regional disparities, currently the social security, pension and public service systems are far more developed in urban than rural areas. The rural social security system's obsolete design and inadequate funding levels prohibit rural residents from enjoying the same social security resources as urban residents [11]. For example, in urban areas, high income workers have comparatively complete pension security through the government subsidized system: in rural areas, a large number of rural residents with relatively low incomes are not eligible for pensions [12].

Another major consideration in deciding retirement location for many is the quality and availability of local medical care. Medical personnel in rural areas lack extensive medical knowledge and the infrastructure is severely underdeveloped [13]. In Shaanxi province, the city has 3857 hospitals and health centers, while the provincial areas have only 1601 rural health centers. In terms of beds, the city has 5.7 beds per thousand people, the rural areas 1.8 beds [14].

There are some countervailing trends which could affect a potential retiree's assessment of rural medical care. The New Rural Cooperative Medical system (NCMS) — which has made great efforts in helping rural residents seek medical services in their hometown-has increased rural residents' willingness to seek treatment in formal medical institutions (rather than, for example, self-treatment) and increased the percentage of patients choosing to be treated in nearby clinics [15]. However, even if medical care is available, people must also know the choices available. Dai et al. [16] suggest that a significant number of rural residents do not understand the NCMS because information within the system is delivered in written documents which migrant workers do not have the time or energy to process. The reimbursement process is slow and complicated; it takes complex procedures to reimburse and transfer accounts to finish a medical billing transaction even when patients are in their registered Hukou; such transactions are far more complicated when the worker is outside their Hukou.

\subsection{Health Consciousness}

The 2016 medical reform in China, a part of which is aimed at improving the rural medical service system, could either act as a pull to return migrants to their rural Hukou or a push towards remaining in the urban areas. Under the new system, China will have a three-tiered rural medical health service network with county hospitals acting as leaders, township health centers as branches and village clinics as the original entry point for general care. County hospitals will be primarily responsible for offering hospitalization, treating patients with severe and emergency illness and will be in charge of the technical guidance of township health centers and village clinics including training health personal in the lower tiers of the system. County health centers will be responsible for offering public health services and comprehensive services towards common diseases, treating frequently occurring diseases and guiding the technical development and health personnel training for village 
clinics. Village clinics are responsible for offering public health services and diagnosing and treating general diseases. It is expected that the new system will increase the overall care and quality of the rural system, thus increasing its attractiveness for migrant workers to return to their registered homes. Yet the new system still concentrates the most intensive medical care in urban areas, which might convince potential returnees that urban areas have the highest quality and most convenient medical care. If so, then educational campaigns promoting medical care reforms designed to increase the quality of the rural medical system might have the ironic effect of depressing migrant workers' willingness to migrate to the rural areas over concerns about the relative quality of the medical care.

\subsection{Smog Consciousness}

In recent years, heavy and persistent smog events in China have aroused serious public concern. These events are mainly caused by high levels of air pollutants (typically particulate matter with an aerodynamic diameter less than 2.5 parts per million (PM). In 2013, the Social Survey Center of the Public Opinion Research Laboratory at Shanghai Jiao Tong University found that respondents' perception of smog is relatively high, while knowledge about pollution is low. More than $80 \%$ of respondents perceived the existence of smog, but only 30\% believed that smog in their cities was serious or knew what formed smog. Urban residents were more aware of smog than suburban residents, who in turn were more aware than rural respondents.

Schikowski et al. [17] indicate an inverse relationship between social status and health impacts from air pollution. Those with lower social economic status (SES) are more likely to be harmed by air pollution, while people with higher social economic status, higher income and higher education have more resources to avoid pollution. Those with high SES, for example, can travel or take a holiday during high smog episodes, while lower SES groups cannot afford to leave.

Smog is also disproportionately harmful to specific groups, such as children and the elderly [18], and there is some evidence that the elderly are disproportionately more supportive of smog abatement efforts. Filippini et al. [19] show that older respondents tend to report higher willingness to pay for improved air pollution. Buehn et al. [20] further indicate that the elderlys' demand for environmental quality is higher than younger residents. In addition, elderly residents are less tolerant of environmental pollution and more likely to demand higher air quality [21]. Given the relationship between SES, age, and smog, it is likely that potential retirees-particularly those with relatively high SES-will include environmental factors in their choice of retirement location.

\subsection{Retirement Decisions}

In general, retirees around the globe prefer aging-in-place, spending early retirement in areas they are familiar with and delaying disability-related relocation as long as possible (e.g., Germany [22,23]). Aging residents who stay in place retain their housing (which they have adapted to suit their personal preferences), their social networks, their friends, their neighborhoods, their personal and social histories with the area and they can maintain relationships with their family members who have also chosen to stay in place $[24,25]$. Studies in Europe and North America-areas with relatively secure retirement incomes-put the numbers of people preferring to retire in place at 70 to 90 percent of all recent retirees [24].

Of those in early retirement who do move, the major patterns in early retirement are snowbird or amenity migration, economic advantage migration, assistance migration or return migration [22,26]. Amenity-driven retirement, whether European or Chinese, generally is for relatively affluent, relatively healthy early retirees who move to areas that provide a higher quality of life whether natural (mountains or coastal regions) areas or built environments (small sized cities, retirement communities with amenities such as pools or spas) $[27,28]$.

Economic advantage migration is geographic arbitrage: retirees offshore their retirement to locations with lower costs of living for day-to-day expenses. Considered particularly attractive for North American retirees with low retirement security, these migrants are trading the advantages of 
in-place retirement for the more affluent lifestyle they can have in other locations. These retirees, then, occupy a different niche than the amenity retirees in that a primary motive is leveraging a more affluent lifestyle. This particular form of migration is closely structured by highly unequal North-South structural relations coupled with migrants who have relatively weak social ties-to family, to place or to collective projects [29]. It is, in a sense, the polar opposite of assistance migration where the retirees move close to caretakers (family or friends), a migration pattern frequently seen with the frail elderly.

Within the retiring population, migrant workers have dual identities, competing relationships and, often, economic ties to both their origin and their adopted residences. How deeply they have been able to assimilate (citizenship status, language ability, economic resources and kinship ties) is the most important determinant of whether or not migrants choose to stay in place or return to their country of origin [30]). As with other retirees, ties to place, being close to family or friends (ties), and the amenities of life are important factors in making a decision, but migrants by definition will have ties and friends in two geographically separate locations and often have economic and even residential ties in both. Significant influences on migrants' decisions include their degree of assimilation, their social and economic resources (including access to health care), and where their children are residing.

Interestingly, research studies that have examined migrant workers have also largely found that the majority of migrants plan to either stay in place or maintain two locations-one in their home country and one in the country they migrated to. For example, the majority of Mexican migrants (62 percent) are planning to retire in the United States; even those who own property in Mexico and who remit money to family in Mexico are only slightly more likely to return to Mexico than those who do not have those ties [22]. Similarly, the data from the German Socio-Economic Panel, which looked at return migration among older immigrants to Germany, found that only 17 percent of immigrants selected to return to their home country [30]. A slightly higher percentage of immigrants to Switzerland intended to return home either part-time or full-time (about a third each) [26].

Given, then, the general literature on migrant retirement, it would be reasonable to expect that the majority of rural-to-urban migrants would in fact choose to remain in urban areas.

\section{Theoretical Model and Hypothesis}

\subsection{Theoretical Model}

Pull-push theory has been universally used in studying migration issues. Bogue [31] first proposed pull-push theory arguing that migration decisions are a balance of pulls (which discourage migration) and pushes (which promote migration). In rural areas, the original migration decisions are likely to be influenced by diminishing natural resources, increasing agricultural costs, surplus labor and economic distress (low income levels) —all potential forces promoting migration-while family membership in rural areas, the desire for a familiar environment and attachment to local social networks are the factors pulling them back. In the urban areas, better developing opportunities, higher income, advanced living standards, and cultural infrastructure might be pushing forces while the strange environment, fierce competition and a deteriorated ecological environment might pull migrants. Many—but not all—of these same factors are likely to be relevant for retirement decisions.

While the lure of higher incomes and better job opportunities are the main pulling factors attracting migrants to urban areas, retirees might be more concerned with the urban area's more expensive living conditions and be less attracted to the better work opportunities as health and age limit their ability to take advantage of these opportunities. In addition, while migrant workers tend to be a relatively healthy population focused on economic opportunities, retirees tend to be more concerned about medical issues (both their personal health and the availability of medical care) and the quality of the environment. Migrant workers who have higher incomes, more opportunities, and higher educational levels are likely to be pulled to urban amenities, while those who have supportive medical infrastructures (such as insurance), property or elderly relatives in the rural areas are likely to be pushed to the rural areas. The theoretical structure is outlined in Figure 1. 


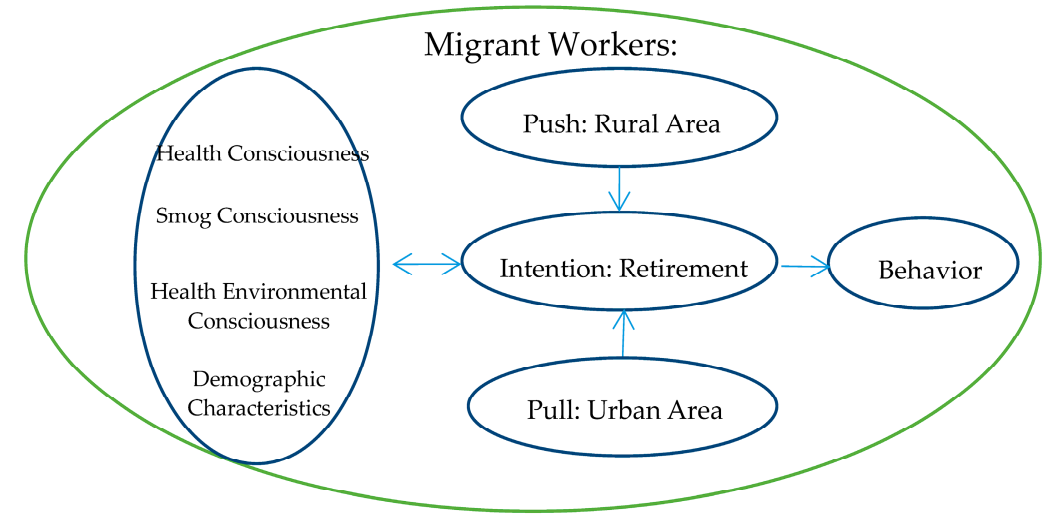

Figure 1. The conceptual mode of elder migrant workers' preferred retirement place.

\subsection{Hypothesis}

Health consciousness may influence elder migrant workers' preferred place of retirement. Yang et al. [32] point out that migrant workers in urban areas have always lived at the edge of the society, socially and economically. The vast majority of migrant workers face poor conditions in their areas of destination, including work conditions, living environment, social integration and support. They do not enjoy equal rights as urban residences in social security, public services, etc. Rural Hukou residents, for example, receive lower pension payments and public services due to the lagging economic conditions in rural areas. Yang et al. [32] also propose that health problems are a major issue for all migrant workers. A majority of migrant workers live in dormitory-style accommodations provided by the work unit, sharing their space with several other workers and using outside amenities for tap water and toilets [33]. These places are crowded, with poor health facilities, and simple unhygienic canteens. All were unsanitary enough to promote and spread bacterial growth, especially intestinal infectious diseases.

While the health conditions are objectively bad, migrant workers might not recognize the health implications of their living conditions. According to Yuan et al. [34], those who live in the rural areas have limited knowledge of basic health education. Their superficial understanding combined with a general tendency to describing their personal health as good, leads to a general acceptance of current physical conditions, even though rural areas always have urgent health issues and demands. Their overall low level of health education might also limit migrant workers' consciousness of health conditions in urban areas, although interaction with urban, educated workers and urban media could potentially increase their awareness. Hence, there is a strong possibility for a range of physical health awareness among migrant workers. Presumably, though, those who are most aware of the health implications of their current environment would also be most likely to wish to change those conditions.

Hypothesis 1 (H1). The higher the personal health consciousness, the more likely migrant workers will choose rural areas for retirement.

Objectively speaking, rapid economic growth has led to severe air pollution [35-37]. Further, population increases in urban areas are decreasing the environmental carrying capacity of land resources [38]. All of these degradations harm human health, are increasingly publicly acknowledged and have led to increasing pro-environmental attitudes and environmental participation [39].

Knowledge of environmental problems is more publicized and more known in urban areas, even though environmental problems are, in fact, worse in the rural areas. From the very beginning of government environmental information disclosures, information about air pollution was much more widespread and easier to track than information about soil pollution, water pollution or sound pollution. People can easily track real-time information about air pollution through their phones, websites, etc. as well as just being able to track air pollution visually. (For example, it is easy to 
retrieve the air quality index and the major pollutant, such as PM2.5, PM10, etc. at the data center of Environmental Protection Department of China, which is published hourly.) The frequent appearance of smog days not only brings a negative impact on people's health and daily life, but also increases their concerns about air quality [40]. Given that the pollution most commonly associated with urban areas (smog) is far more widely publicized than the environmental impacts more closely linked to rural pollution (soil and water contamination), it is likely that increases in consciousness about smog would act as a push away from urban retirement. Therefore, hypothesis 2 is proposed.

Hypothesis 2 (H2). The higher the migrant's smog consciousness, the higher the likelihood they will choose rural areas for retirement.

The particular types of illnesses and environmental contaminants in the urban areas are particularly visible to migrant workers. With the influx of a great number of migrant workers, bacteria and viruses easily spread in their working environment, particularly given the often cramped and congested living conditions that the lower paid migrant worker can afford. In addition, migrant workers are particularly likely to be employed in secondary $(56.6 \%$, including manufacturing and building trade), and tertiary ( $42.9 \%$, including transportation, postal, wholesale and retail work and tourism) industries. These types of jobs are disproportionately likely to be outdoors and therefore to chronically expose the migrant workers to urban smog. Migrant children as well are more likely to be exposed to physical health risks and have only limited ability to utilize health services [41], spreading the migrant worker's concerns more broadly to their family as a whole. Given that the migrants are likely to have more access to medical services and family support networks in their Hukou [42], hypothesis 3 is proposed.

Hypothesis 3 (H3). The more that migrant workers indicate that the environment in urban areas is affecting their or their family's health, the higher the likelihood for them to choose rural areas for retirement.

Demographic variables such as educational background, age, insurance, income, property and family size are also known to influence elder migrant workers' preferred place of retirement. According to Li et al. [43], people with higher educational levels prefer urban areas for retirement. Elderly migrant workers who have parents at home are more likely to return home, obeying the traditional Chinese custom that children should not live far away from their parents. Since elderly rural residents do not have the necessary endowments and medical security, they must rely on their children to look after them. If migrant workers cannot adequately care for their parents in urban areas, they have to return home.

As for insurance, the rural social security system is the weakest part of the social security system in China [44]. Specifically, rural social security payments are lower for rural Hukou recipients and therefore rural to urban migrants are less able to afford to retire in urban areas. In addition, migrant workers tend to migrate to the more dynamic and more expensive urban areas which means that-when it comes time to retire-the less expensive rural areas might become more appealing, particularly given that migrant workers tend to live in illegal buildings with insufficient public infrastructure, etc. [45]. Smith [46] proposes that migrant workers' mobility makes them unwilling to buy or rent better-and more expensive-urban houses prior to retirement. As a result, migrant workers have fewer ties to the urban area when deciding retirement location. This paper also includes demographic variables such as educational background, age, insurance, income, property and family size to examine elder migrant workers' preferred place of retirement.

\section{Methodology}

\subsection{Sample Selection}

The data used in this paper come from an empirical survey of migrant workers in $\mathrm{Xi}^{\prime}$ an, the capital city of Shaanxi province. According to the National Bureau of Statistics, the GDP in China and 
Shaanxi province was 50 thousand RMB (7.2 thousand USD) per capital and 48 thousand RMB (6.9 thousand USD) per capital, respectively, in 2015. Xi' an has the highest GDP per capita of all cities in Shaanxi province at 67 thousand RMB (9.7 thousand USD) per capita, and attracts the most migrant workers. There are 1.3 million migrant workers in $\mathrm{Xi}^{\prime}$ an, $14.9 \%$ of the city population.

Migrant workers lean heavily to the construction and service industries in Xi'an; $18 \%$ of migrant workers were employed in these industries in 2015. Interviews were collected at construction sites and at the bus station. We contacted the construction site managers and obtained their name lists, then we chose the samples with a random number table. Interviewers recorded all information from the questionnaires.

\subsection{Questionnaires}

There were two questionnaires used in this study. Questionnaire A, also called the "Family Questionnaire," was given to migrant workers between 20 and 65 years old who had an "agricultural Hukou" and no less than six months' living experience in urban cities. For questionnaire A, there were 705 samples. Questionnaire A includes family condition, job and income, public service, social security, living and dwelling condition, and social integration. An additional Questionnaire B, also called the "Individual Health Questionnaire," was distributed to survey respondents within the larger sample who were over 45 years old. The effective rate of sampling for this additional instrument was $86.9 \%$ (173 valid samples out of 199 potential interviewees). Questionnaire B covered basic health information including smoking background, eating habits, medical insurance and service, illness history, living, working environment and self-perception of health status. Blood pressure (Questionnaire B) was measured during the interview.

According to the Chinese Statistical Yearbook of 2016, 27.87\% of the population were between 45 and 65 (not including 65 years old) in China in 2015; the sample population was quite similar, with $24.26 \%$ of the sample between the ages of 45 and 65 . The sample educational status closely matches the latest educational data in the China Rural Statistical Yearbook of 2015, indicating relatively high generalizability (sample data: 53.18\% middle school, 22.54\% primary school, 19.8\% high school; population data: $53.03 \%$ middle school, $26.06 \%$ primary school; $10.01 \%$ high school in 2012 ).

\subsection{Model and Scale Construction}

With multinomial logistic regression, the regression mode is listed below.

$$
\mathrm{Y}=\mathrm{F}\left(\mathrm{INTENSION}, \mathrm{X}_{\mathrm{i}}, \mathrm{c}\right)
$$

$\mathrm{Y}$ is a dependent variable ( $\mathrm{Y}=1$, stay outside for retirement; $\mathrm{Y}=2$, return home for retirement; $\mathrm{Y}=3$, have not thought about it, which is the reference group). Regarding PHCI (personal health consciousness), SMCON (consciousness towards the concern of smog), SMINF (consciousness towards the influence of smog), and HECI (health-environmental consciousness) as explanatory variables, $X_{i}$ is the control variable, and $\mathrm{c}$ is a disturbance term. The specific mode follows below.

$$
\begin{gathered}
\mathrm{Y}=\beta_{0}+\beta_{1} \mathrm{PHCI}+\beta_{2} \mathrm{SMCON}+\beta_{3} \mathrm{SMINF}+\beta_{4} \mathrm{HECI}+\beta_{5} \mathrm{INSUR}+\beta_{6} \mathrm{SIZE}+\beta_{7} \mathrm{AGE}+ \\
\beta_{8} \text { EDUCA }+\beta_{9} \mathrm{INCOME}+\beta_{10} \mathrm{PROPERTY}+\beta_{11} \mathrm{BLPR}+\alpha
\end{gathered}
$$

Explanatory variables and survey questions on these variables are listed below.

Table 1 includes the details of each variable. PHCI represents the personal health consciousness of the interviewee, ranked from 1 to 5 . SMCON and SMINF represent the smog consciousness of interviewee. SMCON is measured by four degrees $(1=$ little concern to $4=$ always concerned), while SMINF is measured by three degrees $(1=$ little influence to $3=$ obvious influence). HECI represents the health-environmental consciousness of interviewee, awarded from 1 to 5 . INSUR (insurance) is a 0-1 dummy variable indicating whether migrant workers have joined in the new rural cooperative medical system or not. SIZE (family size) represents the immediate family member 
of interviewees, including spouse, child and parent, including those living with the migrant and those back in the migrant's hometown. AGE represents the age of interviewees. EDUCA (educational level) represents the educational level of interviewees. INCOME represents the income of interviewees, documenting one's income of last month or job without including the food and accommodation provided. PROPERTY is a dummy variable indicating whether the migrant worker has bought or built a house in the hometown in rural areas. BLPR (blood pressure) represents the blood pressure of interviewees; the normal range of low pressure is 60-90 while the normal range of high pressure is 90-130. As long as one's blood pressure is either in the high range or the low range, it is abnormal and denoted as 0,1 is for normal.

Table 1. Survey questions on explanatory variables and scales.

\begin{tabular}{|c|c|}
\hline Variables & Questions and Answers \\
\hline \multirow[t]{2}{*}{ PHCI } & $\begin{array}{l}\text { Compared with your health status five years ago, what do you think of your health } \\
\text { status now? }\end{array}$ \\
\hline & $1=$ very poor; $2=$ poor; $3=$ fair $; 4=$ good $;=$ very good \\
\hline \multirow{2}{*}{ SMCON } & How often do you pay attention to smog? \\
\hline & $1=$ little concern; 2 = occasional concern; $3=$ regular concern; $4=$ always concern \\
\hline \multirow{2}{*}{ SMINF } & Does smog influence you and your family's normal life? \\
\hline & 1 = little influence; 2 = some influence; 3 = obvious influence \\
\hline \multirow[t]{2}{*}{ HECI } & $\begin{array}{l}\text { Are you willing to stay in urban areas if you have noticed the negative influence of } \\
\text { working environment toward your health even if with the huge income? }\end{array}$ \\
\hline & 1 = very willing; 2 = willing; 3 = fair; $4=$ unwilling; 5 = very unwilling \\
\hline \multirow{2}{*}{ INSUR } & Have you joined in the new rural cooperative medical system? \\
\hline & $1=$ yes; $0=$ no or don't know \\
\hline \multirow[b]{2}{*}{ SIZE } & How many family members do you have, including spouse, child and parent? \\
\hline & $\begin{array}{l}1=\text { one person; } 2=\text { two persons; } 3=\text { three persons; } 4=\text { four persons } ; 5=\text { five persons; } \\
6=\text { six persons; } 7=\text { seven persons }\end{array}$ \\
\hline AGE & How old are you? \\
\hline \multirow[t]{2}{*}{ EDUCA } & What's your education level? \\
\hline & $\begin{array}{l}0=\text { never been to school } ; 6=\text { primary school } ; 9=\text { middle school } ; 12=\text { high school } \\
13=\text { specialized secondary school } ; 15=\text { junior college } ; 16=\text { undergraduate college; } \\
19=\text { graduate college }\end{array}$ \\
\hline INCOME & $\begin{array}{l}\text { What's your income last month or the present job, without including the food and } \\
\text { accommodation provided? }\end{array}$ \\
\hline \multirow{2}{*}{ PROPERTY } & Have you bought or built a house at hometown in rural areas \\
\hline & $1=$ yes; $0=$ no \\
\hline \multirow[b]{2}{*}{ BLPR } & Measuring the blood pressure of interviewees with instrument. \\
\hline & $\begin{array}{l}1=\text { normal (systolic blood pressure: } 90-130 \text {; diastolic blood pressure: } 60-90 \text { ); } 0=\text { abnormal } \\
\text { (systolic blood pressure: }<90,>130 \text {; diastolic blood pressure: }<60,>90 \text { ). }\end{array}$ \\
\hline
\end{tabular}

\section{Results}

\subsection{Descriptive Statistics of Dependent Variable}

The descriptive statistics in Table 2 show that 70.5\% of the sample choose to return home for retirement, $16.8 \%$ stay away from home, and $12.7 \%$ have not considered the question.

The personal health consciousness is between poor and fair, with a mean of 2.62, while their lack of concern about smog indicated that they were most likely to believe that the smog levels had little to some effect on their health (mean 1.76). They certainly did not have high levels of concern about smog 
(with a mean of 2.16 out of a potential high of 4.0). The mean health environmental consciousness was 2.63, between willing and fair.

Over half $(55.49 \%)$ of the sample respondents have joined the new rural cooperative medical system. The mean family size is roughly five people per family (mean 4.74). The average age is 50.42. The mean educational level is 8.65 , closest to "middle school". The mean income is $4002 \mathrm{RMB}$ (579 USD) per month, higher than the average income (3072 RMB, which is 445 USD, measured by the National Bureau of Statistics) of migrant workers per month in 2015, but slightly lower than the average urban income nationwide 4697 RMB (680 USD) or in Shaanxi (4211 RMB (610 USD) [47]. Most, $75.72 \%$, have their own houses, either bought or built. In terms of blood pressure, only $54.34 \%$ have a normal blood pressure reading (systolic blood pressure, 58.38\% register normal; diastolic blood, $74.57 \%$ normal).

According to Table 2, elderly migrant workers who preferred to stay outside their original hometowns for retirement have better personal health consciousness, smog consciousness and health environmental consciousness and better health status than those who preferred to return to their hometown for retirement. Among the samples, $41.38 \%$ have joined the new rural cooperative medical system. They had a small family, and $44.83 \%$ bought or built their own houses in their hometown. They were also likely to belong to smaller families; counterintuitively, they were less likely to have a higher education.

Elderly migrant workers who preferred to return home for retirement generally felt less healthy, but were also less worried about the smog and less likely to feel that the smog was changing their or their family's activities. These rural bound workers were also more likely to prepare to return to their original homes. Over half $(61.48 \%)$ have joined the new rural cooperative medical system and the vast majority $(81.9 \%)$ have bought or built a house in their hometown.

Table 2. Characteristics of variables.

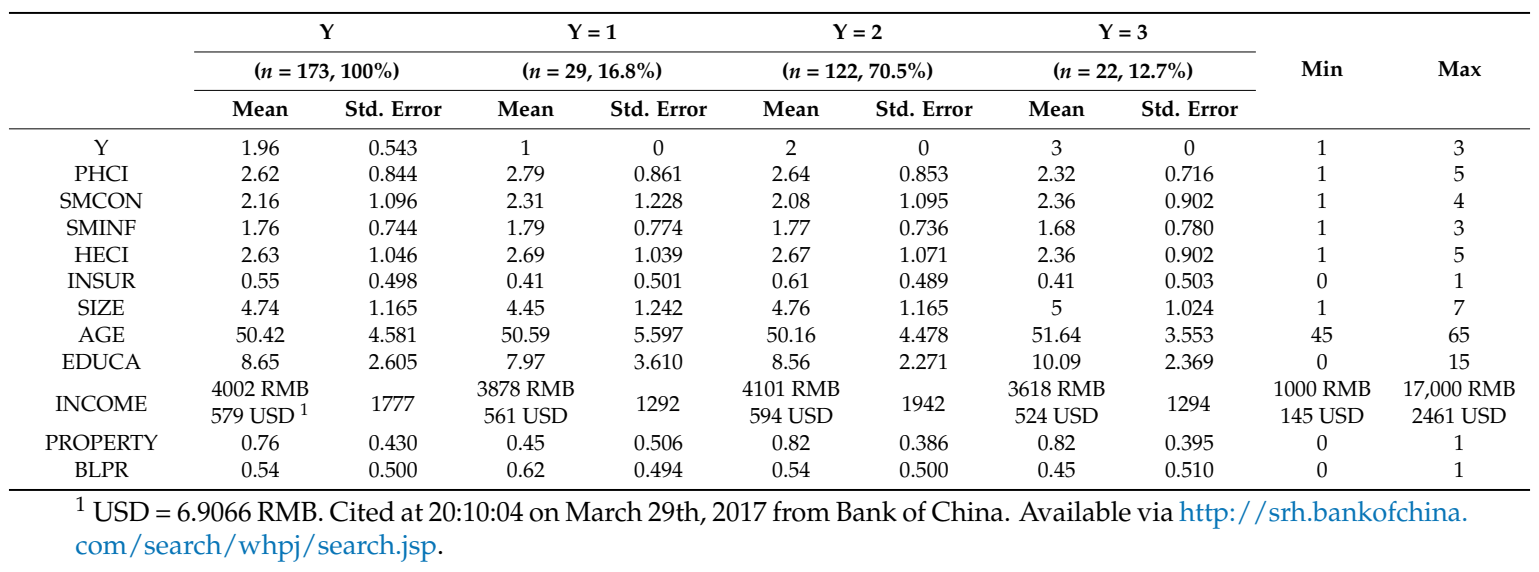

\subsection{Multinomial Logistic Regression}

In order to further explore the relations among health consciousness, smog consciousness, health environmental consciousness and elderly migrant workers' selection of retirement place, the authors ran a multinomial logistic regression based on the data using $(Y=3)$ as a reference group. The result is listed below.

As for $Y(Y=1)$ in Table 3, the PHCI variable $(z=1.93, p<0.1)$ has a significant positive relationship with elderly migrant worker's preferred place (away from home) for retirement. EDUCA $(z=-2.83$, $p<0.01)$ and PROPERTY $(z=-2.27, p<0.05)$ have a significantly negative relationship with elderly migrant worker's preferred place (away from home) for retirement. Other tested variables-SMCON, SMINF, HECI, INSUR, SIZE, AGE, INCOME and BLPR—do not have significant correlations with the preferred retirement place (away from home) of elderly migrant workers. 
As for $\mathrm{Y}(\mathrm{Y}=2)$, the PHCI variable $(z=2.18, p<0.05)$ has a significantly positive relation with elderly migrant worker's preferred place (hometown) for retirement (H1 accepted). The SMCON variable $(z=-1.88, p<0.1)$ and EDUCA variable $(z=-2.58, p<0.01)$ are negatively correlated with elderly migrant worker's preferred retirement location (hometown) (H2 rejected for SMCON). Additional variables, SMINF, HECI, INSUR, SIZE, AGE, INCOME, BLPR and PROPERTY, do not have significant effects on the preferred retirement place (hometown) of elderly migrant workers (H3 rejected).

Table 3. Regression model.

\begin{tabular}{|c|c|c|c|c|c|c|}
\hline & \multicolumn{3}{|c|}{$Y=1$} & \multicolumn{3}{|c|}{$Y=2$} \\
\hline & \multicolumn{3}{|c|}{$(n=29,16.8 \%)$} & \multicolumn{3}{|c|}{$(n=122,70.5 \%)$} \\
\hline & Coefficient & Std. Error & $\mathbf{P}(Z)$ & Coefficient & Std. Error & $\mathbf{P}(\mathrm{Z})$ \\
\hline PHCI & $0.819 *$ & 0.423 & $0.053(1.93)$ & $0.802 * *$ & 0.368 & $0.029(2.18)$ \\
\hline SMCON & -0.408 & 0.360 & $0.258(-1.13)$ & $-0.562 *$ & 0.300 & $0.060(-1.88)$ \\
\hline SMINF & 0.642 & 0.512 & $0.210(1.25)$ & 0.571 & 0.423 & $0.177(1.35)$ \\
\hline HECI & 0.288 & 0.343 & $0.402(0.84)$ & -0.285 & 0.295 & $0.333(-0.97)$ \\
\hline INSUR & 0.012 & 0.669 & $0.985(0.02)$ & 0.590 & 0.547 & $0.281(1.08)$ \\
\hline SIZE & -0.193 & 0.299 & $0.518(-0.65)$ & -0.034 & 0.252 & $0.893(-0.13)$ \\
\hline AGE & -0.109 & 0.074 & $0.142(-1.47)$ & -0.092 & 0.059 & $0.117(-1.57)$ \\
\hline EDUCA & $-0.426^{* * *}$ & 0.150 & $0.005(-2.83)$ & $-0.335^{* * *}$ & 0.130 & $0.010(-2.58)$ \\
\hline INCOME & 0.00009 & 0.0002 & $0.649(0.46)$ & 0.00020 & 0.0002 & $0.250(1.15)$ \\
\hline PROPERTY & $-1.723 * *$ & 0.760 & $0.023(-2.27)$ & 0.006 & 0.679 & $0.993(0.01)$ \\
\hline BLPR & 0.527 & 0.667 & $0.429(0.79)$ & 0.132 & 0.536 & $0.806(0.25)$ \\
\hline Cons & 8.131 & 5.035 & $0.106(1.61)$ & 6.141 & 4.165 & $0.140(1.47)$ \\
\hline
\end{tabular}

Level of significance: ${ }^{* * *} p<0.01 ;{ }^{* *} p<0.05 ;{ }^{*} p<0.1$.

\section{Conclusions and Discussion}

This research project explores the relation between health consciousness, smog consciousness, health environmental consciousness and preferred retirement location for 173 elderly migrant workers in $\mathrm{Xi}^{\prime}$ an. The most surprising result is that-contrary to most studies of migrant retirement decisions - the vast majority $(70.5 \%)$ preferred to return home for retirement. Less than one fifth $(16.8 \%)$ indicated that they were more likely to not return to their original agricultural Hukou, a startling reversal of most migrant retirement patterns. Our presumption is that to have such a small percentage intent to stay in the area in which they were employed indicates systematic and large impediments to assimilation in urban areas. While, unfortunately, our survey did not include questions that would directly test this, the findings in our study are starkly different to studies of migrants in other countries. European and North American migrants with more intense language and cultural differences between home and the adopted country are far more likely to stay at least part of the year in their adopted country.

One of the few variables that predicted intent for the Chinese migrant was property ownership. As expected, those who had bought or built houses at home were more likely to say that they would return home for retirement, although given the cross-sectional nature of the data collection, causality cannot be inferred. (The decision to buy and build property could either precede or follow the decision on where to retire.) However, the decision to buy property by definition links the migrant to the location where he or she bought property and general theory suggests that established ties are an important factor in retirement decisions, as is previous knowledge of and experience with the area the retiree is moving to.

Personal assets are the final important element influencing an individual's choice of retirement place, including house property, pension, medical insurance, family income, etc. Among all the samples, $75.72 \%$ of migrants own houses, either bought or built, in their hometown. Migrant workers seldom have the ability to buy real estate in urban areas, and they are in an inferior position in the housing 
market. Compared with urban residents, they lack fair support in the type, quality, infrastructure, and environment condition of housing [48]. For most people, housing represents their major economic and personal investment, owning or renting a house symbolizes the social and economic status of an individual, even a family [49,50]. A majority of our samples have the ability to buy or build their own houses in their hometown. In urban areas, most migrant workers live in rented houses on the city outskirts or in dormitory-style accommodations with public toilet facilities [51]. Houses in urban areas are generally too expensive for many migrant workers. When expected residency is limited, migrant workers are strongly disincentivized from investing time and money in either their temporary living places or employer-based insurance programs, even to invest in their personal health and safety [52].

INSUR, insignificant in the regression model, is likely affected by the limited medical services offered under the new rural medical service system. Under the new rural medical system China will have a three-tiered rural medical health network with county hospitals acting as leaders, township health centers as branches and village clinics as the original entry point for general care. Rural elderly persons returning to rural areas would only be eligible for limited care in the rural areas, while rural Hukou elderly living in urban areas would also find it difficult to receive medical services in the cities. Therefore, at this point, residents have relatively little to distinguish the two systems in terms of care, although that may change as the new system becomes more established and its advantages and limits more widely known.

Personal health consciousness had a complex relationship with future retiree's decision on where to retire. For those who intended to return to their home Hukou, the higher the personal health consciousness, the more likely they were to return to their original hometown. For those who intended to stay in urban areas, the higher the personal health consciousness, the more likely they were to retire to urban areas. In terms of staying in the urban areas, counterintuitively, the higher their smog consciousness, the less likely the migrant workers were to return to agricultural areas for retirement.

The other main explanatory variable, educational background, also had a complex relationship with intention to return home. For the home-bound retirees, the higher the educational level, the less likely they were to return to their original hometown. For those who intended to stay in urban areas, the higher the educational level, the less likely they were to retire to urban areas, although again, the overall educational level for all migrant workers was very low.

Smog consciousness occupies a vital—although ironic—role in influencing elder migrant workers' preferred retirement location. While it seems intuitively obvious that the visibility of smog and the relatively widely publicized health hazards associated with "smog weather" would pull migrant workers back to rural areas, those migrant workers who were most concerned with smog were also the most likely to wish to retire in urban areas. One potential explanation is that those people who were specifically concerned with smog pollution are also concerned with pollution in general. If so, the promotion of environmental consciousness in China and the serious pollution in rural areas might lead elderly migrant workers to choose urban areas for retirement. The higher perceived health recognition, self-evaluation of health status and living satisfaction of the elderly living in urban areas found in the study support this argument. (However, it should be noted that the actual ability of rural elderly persons to conduct daily self-care activities (ADL) is higher than in urban areas.)

In terms of policy recommendations, it is important to note that (a) some 70 percent of the migrants are currently planning to return to their agricultural Hukou; (b) it is highly likely that this unusual pattern is the result of systematic blocks to assimilation; and (c) the return migration will put a heavy burden on already limited rural support services.

Changes in government policy, however, could greatly moderate the original pushes to leave the rural areas, giving more stability to the demands on the rural infrastructures serving the aging populations. The rapid development of rural economy and government policies developed specifically to encourage college graduates has indeed inspired many graduates to start their own businesses in rural areas. Relevant government departments have established "innovation zones" for college graduates to start agricultural science research in rural areas. These projects not only potentially 
provide agriculture with more space, but also give college graduates more opportunities. In addition, some areas have promoted small startup loans for college graduates, pilot projects that will be expanded nationwide. In 2016, Chen, the deputy directory of Ministry of Agriculture of the People's Republic of China, claimed that the percentage of migrant workers and college graduates who returned to their areas of origins to start their businesses had doubled. By the end of 2015, the number of migrant workers who returned their hometown for business was already over 4.5 million $(2 \%$ of all the migrant workers), with the percentage of college graduates who returned home for business increased from $0.5 \%$ to $1 \%$. However, given the relatively small rate of migrant worker return during their economically productive years, these programs currently are not enough to counter migration. Therefore, more supportive policies should be developed that will (a) encourage people to invest or develop rural areas; and (b) equalize rural-urban education, including increasing technical skills training in rural areas.

Working on the other end by reducing return migration, policies that increase the ability of migrants to build personal or family capital in the areas they migrate to could decrease retiree's return migratory behavior by removing blocks to assimilation. Liberalizing the Hukou system could also free them from some related migration burdens, which may in turn encourage the original migratory behaviors but decrease return migration. As China moves into an aging society, it is likely that some of the restrictions on "Hukou" and an increase in the equalization of public services in the pension service, medical service, education, etc. will affect retirement choices in the future in complex and interactive ways.

Acknowledgments: We would like to thank the anonymous reviewers for very helpful suggestions and comments. The work on this paper is supported by the National Social Science Foundation of China (No. 15XGL017), Zhejiang Provincial Natural Science Foundation of China (No. LZ13G030001), and Zhejiang Provincial Social Science Foundation of China (No. 17NDJC029Z).

Author Contributions: Feng Wang came up with the original idea for this article, helped to draft and review the manuscript. Jin Fan wrote most of the manuscript, and communicated with the editor of the journal. Ann Reisner helped to write and revise the manuscript. Hong Mi conceived, designed, and conducted the research. All authors read and approved the final manuscript.

Conflicts of Interest: The authors declare no conflict of interest.

\section{References}

1. Zachary, Z.; Ming, W.; Toshiko, K. A multi-level analysis of urban/rural and socioeconomic differences in functional health status transition among older Chinese. Soc. Sci. Med. 2010, 71, 559-567.

2. Solinger, D.J. Citizenship issues in China's internal migration: Comparisons with Germany and Japan. Political Sci. Q. 1999, 114, 455-478. [CrossRef]

3. Zhang, Y.L. Migrant workers in counties and towns. Soc. Commun. 1984, 1, 286-296.

4. National Bureau of Statistics of China. National Bureau of Statistics of China: Responses to Reporters on Operation of National Economy about the First Half Year in 2015. Available online: http:/ / www.stats.gov. cn/tjsj/sjjd/201507/t20150715_1215420.html (accessed on 19 March 2017).

5. Social Insurance Administration, Ministry of Human Resources and Social Security. Annual Development Report of Chinese Social Insurance (2014); China Labour and Social Security Publishing House: Beijing, China, 2015.

6. Knight, J.; Gunatilaka, R. Great expectations? The subjective well-being of rural-urban migrants in China. World Dev. 2010, 38, 113-124. [CrossRef]

7. Yuan, H.N. Migrant workers' health and income-Based on the survey of migrant workers in Beijing. Manag. World 2009, 5, 56-66.

8. Li, Q. Urban Migrant Workers and Social Stratification in China; Social Sciences Academic Press: Beijing, China, 2012.

9. Lin, P. A Survey on Young Migrant Workers. 2014. Available online: http://www.cucc.org.cn/html/74-3/ 3087.htm (accessed on 19 March 2017). 
10. Chu, R.W.; Hail, H.C. Winding road toward the Chinese dream: The U-shaped relationship between income and life satisfaction among Chinese migrant workers. Soc. Indic. Res. 2014, 118, 235-246. [CrossRef]

11. Donald, J.T. The "difference between heaven and earth": Urban-Rural disparities in well-being in China. Res. Soc. Stratif. Mobil. 2012, 30, 33-47.

12. Li, S.Y.; Feng, J.X. The economic effects of China's new pension system for urban and rural residents: Simulations based on Auerbach-Kotlikoff model. Econ. Rev. 2014, 187, 3-15.

13. Kristi, H.; LouAnn, H.W.; Kristen, C.I.; Jonathan, W.; Richard, L.S. Prevalence of intubation rescue by air medical personnel during transfers from rural emergency departments. Air Med. J. 2015, 34, 141-143.

14. Shaanxi Provincial Bureau of Statistics; National Bureau of Statistics Survey Office in Shaanxi. Shaanxi Statistical Yearbook of 2015; China Statistics Press: Beijing, China, 2015.

15. Jiang, J.Q. NCMS and the change of health care provider choices of rural people. China Popul. Resour. Environ. 2014, 24, 199-202.

16. Dai, X.L.; Dai, X.Y. An analysis on problems and strategies of NCMS. Agric. Econ. 2013, 6, 17-18.

17. Schikowski, T.; Sugiri, D.; Reimann, V.; Pesch, B.; Ranft, U.; Krämer, U. Contribution of smoking and air pollution exposure in urban areas to social differences in respiratory health. BMC Public Health 2008, 8, 179. [CrossRef] [PubMed]

18. Sacks, J.D.; Stanek, L.W.; Luben, T.J.; Johns, D.O.; Buckley, B.J.; Brown, J.S.; Ross, M. Particulate matter-induced health effects: Who is susceptible? Environ. Health Perspect. 2011, 119, 446-454. [CrossRef] [PubMed]

19. Filippini, M.; Martínez-Cruz, A.L. Impact of environmental and social attitudes, and family concerns on willingness to pay for improved air quality: A contingent valuation application in Mexico City. Lat. Am. Econ. Rev. 2016, 25. [CrossRef]

20. Buehn, A.; Farzanegan, M.R. Hold your breath: A new index of air pollution. Energy Econ. 2013, 37, $104-113$. [CrossRef]

21. Tonn, B.E.; Waidley, G.; Petrich, C. The ageing US population and environmental policy. J. Environ. Plan. Manag. 2001, 44, 851-876. [CrossRef]

22. Aguilera, M.B. Deciding where to retire: Intended retirement location choices of formerly undocumented Mexican migrants. Soc. Sci. Q. 2004, 85, 340-360. [CrossRef]

23. Monk, A. The Columbia Retirement Handbook; Columbia University Press: New York, NY, USA, 2010.

24. Kramer, C.; Pfaffenback, C. Should I stay or should I go? Housing preference upon retirement in Germany. J. Hous. Built Environ. 2016, 31, 239-256. [CrossRef]

25. Longino, C.F.; Perzynski, A.T.; Stoller, E.P. Pandora's briefcase: Unpacking the retirement migration decision. Res. Aging 2002, 24, 29-49. [CrossRef]

26. Bolzman, C.; Fibbi, R.; Vial, M. What to do after retirement? Elderly migrants and the question of return. J. Ethn. Migr. Stud. 2006, 32, 1359-1375. [CrossRef]

27. Ma, A.; Chow, N.W.S. Economic impact of elderly amenity mobility in southern China. J. Appl. Gerontol. 2006, 25, 275-290. [CrossRef]

28. Kordel, S. The production of spaces of the 'good life'-The case of lifestyle migrants in Spain. Leis. Stud. 2016, 35, 129-140. [CrossRef]

29. Hayes, M. 'We gained a lot over what we would have had': The geographic arbitrage of North American lifestyle migrants to Cuenca, Ecuador. J. Ethn. Migr. Stud. 2014, 40, 1953-1971. [CrossRef]

30. Yahirun, J.J. Take me "home": Return migration among Germany's older immigrants. Int. Migr. 2014, 52, 231-254. [CrossRef] [PubMed]

31. Bogue, D.J. Internal Migration. In The Study of Population. An Inventory and Appraisal; Hauser, P.M., Duncan, O.D., Eds.; University of Chicago Press: Chicago, IL, USA, 1959; pp. 486-509.

32. Yang, T.Z.; Xu, X.C.; Li, M.; Rockett, I.R.; Zhu, W.; Ellison-Barnes, A. Mental health status and related characteristics of Chinese male rural-urban migrant workers. Commun. Ment. Health J. 2012, 48, 342-351. [CrossRef] [PubMed]

33. Li, L.; Wang, H.M.; Ye, X.J.; Jiang, M.M.; Lou, Q.Y.; Hesketh, T. The mental health status of Chinese rural-urban migrant workers. Soc. Psychiatry Psychiatr. Epidemiol. 2007, 42, 716-722. [CrossRef] [PubMed]

34. Yuan, F.; Qian, D.F.; Huang, C.L.; Tian, M.M.; Xiang, Y.X.; He, Z.F.; Feng, Z.C. Analysis of awareness of health knowledge among rural residents in Western China. BMC Public Health 2015, 15, 1-8. [CrossRef] [PubMed]

35. World Bank. World Development Indicator 2007; China Financial and Economic Publishing House: Beijing, China, 2007. 
36. Douglas, S.B. Chinese ecocriticism: A survey of the landscape. Lit. Compass 2015, 12, 396-403.

37. Lan, Y.Y.; Jin, M.G.; Yan, C.; Zou, Y.Q. Schemes of groundwater exploitation for emergency water supply and their environmental impacts on Jiujiang City, China. Environ. Earth Sci. 2015, 73, 2365-2376. [CrossRef]

38. Elizabeth, E. Environmental governance in China: State control to crisis management. Am. Acad. Arts Sci. 2014, 143, 184-197.

39. Salitskii, A.I.; Chesnokova, S.V.; Shakhmatov, A.V. New energy engineering in the industrial transformation of modern China. Her. Russ. Acad. Sci. 2014, 84, 146-151. [CrossRef]

40. Cheng, P.; Wei, J.C.; Ge, Y. Who should be blamed? The attribution of responsibility for a city smog event in China. Nat. Hazard 2017, 85, 669-689. [CrossRef]

41. Sun, X.Y.; Chen, M.T.; Chan, K.L. A meta-analysis of the impacts of internal migration on child health outcomes in China. BMC Public Health 2015, 16, 1-11. [CrossRef] [PubMed]

42. Zhang, L.W.; Liu, S.S.; Zhang, G.Y.; Wu, S.L. Internal migration and the health of the returned population: A nationally representative study of China. BMC Public Health 2015, 15, 719. [CrossRef] [PubMed]

43. Li, Q.; Long, W.J. Factors influencing migrant workers' willingness of staying at urban areas and returning to rural areas. Chin. Rural Econ. 2009, 2, 46-54.

44. Li, D.Y. NCMS: Present situation and policy suggestions. Philos. Hum. Soc. Sci. 2011, 1, 30-39.

45. Research Group in the Research Office of the State Council. A Report on Chinese Migrant Workers; China Yan Shi Press: Beijing, China, 2006.

46. Smith, C. Living at work: Management control and the dormitory labour system in China. Asia Pac. J. Manag. 2003, 20, 333-358. [CrossRef]

47. National Bureau of Statistics of China. China Statistical Yearbook of 2015; China Statistics Press: Beijing, China, 2015.

48. Wang, G.X.; Su, X.X.; Wen, M. Urban migrants' living conditions and impact on health status: The case of Shanghai. Popul. Res. 2011, 35, 60-72.

49. Freeman, H.L. Mental health and high-rise housing. In Unhealthy Housing; Burridge, R., Ormandy, D., Eds.; E \& FN Spon: London, UK, 1993; pp. 168-190.

50. Stafford, M.; McCarthy, M. Neighbourhoods, housing and health. In Social Determinants of Health; Marmot, M., Wilkinson, R.G., Eds.; Oxford University Press: New York, NY, USA, 2006; pp. 297-317.

51. Peng, Y.C.; Chang, W.H.; Zhou, H.Q.; Hu, H.P.; Liang, W.N. Factors associated with health-seeking behavior among migrant workers in Beijing, China. BMC Health Serv. Res. 2010, 10, 1-10. [CrossRef] [PubMed]

52. Li, X.; Santon, B.; Chen, X. Health indicators and geographic mobility among young rural to urban migrants in China. World Health Popul. 2006, 8, 5-21. [CrossRef] [PubMed] 